\title{
A Note from the Editors
}

As the Editors of Modern Asian Studies, we are sorry that Professor Sundar ${ }^{1}$ is disappointed that Professor Verghese's article, 'British Rule and Tribal Revolts in India', ${ }^{2}$ does not engage with her work in the manner she would have wished. We are in agreement with the reviewers of the article that Verghese sets out a problematic for his study that is posed in a significantly different fashion from Sundar's work. As Verghese explains below ${ }^{3}$, his line of enquiry emerged from comparative questions that had their origins in the field of political science. These questions address issues that do not easily map onto Sundar's ethno-historical work on Bastar.

Modern Asian Studies, with its explicitly interdisciplinary scope, encourages all its authors to be wide ranging in their critical enquiry and generous with their citations. Nevertheless, it is not always selfevident when an author must engage with a particular body of theory. Nor is it clear that such engagement must be on the terms set by the author of that work.

With its robust, double-blind peer review process, Modern Asian Studies first established its academic reputation publishing in the field of history. In recent years it increasingly has become the journal of choice for Asianists publishing in related social science disciplines, including anthropology, sociology, literary criticism, and political science and, as the journal's Editors, we encourage our authors and readers to 'think' across disciplinary boundaries.

Joya Chatterji and Norbert Peabody

\footnotetext{
${ }^{1}$ Sundar, N. (201 7). Letter to the Editors, Modern Asian Studies 51:4, pp. 1220-1221, doi: $10.1017 /$ Soo26749X1700o683.

${ }^{2}$ Verghese, A. (2016). British Rule and Tribal Revolts in India: The curious case of Bastar, Modern Asian Studies 50:5, pp. 1619-1644, doi: $10.1017 /$ Soo26749X1400o687.

${ }^{3}$ Verghese, A. (2017). A Political Scientist Among the Anthropologists, Modern Asian Studies 51:4, pp. 1223-1228, doi: $10.1017 /$ Soo26749X17000701.
} 